\title{
Noise Indicators for Size Distributions of Airborne Particles and Traffic Activities in Urban Areas
}

\author{
Jin Yong Jeon ${ }^{1}$, Joo Young Hong ${ }^{2, *}$, , Sung Min Kim ${ }^{1}$ (I) and Ki-Hyun Kim ${ }^{3}$ (D) \\ 1 Department of Architectural Engineering, Hanyang University, Seoul 04763, Korea; \\ jyjeon@hanyang.ac.kr (J.Y.J.); rainbear0622@gmail.com (S.M.K.) \\ 2 School of Electrical \& Electronic Engineering, Nanyang Technological University, Singapore 639798, \\ Singapore \\ 3 Department of Civil and Environmental Engineering, Hanyang University, Seoul 04763, Korea; \\ kkim61@hanyang.ac.kr \\ * Correspondence: jyhong@ntu.edu.sg; Tel.: +65-8429-7512
}

Received: 6 November 2018; Accepted: 29 November 2018; Published: 5 December 2018

\begin{abstract}
The aim of this study was to explore the relationships among the particle number concentration (PNC), noise, and traffic conditions. Field measurements were conducted to measure the temporal variabilities of the noise levels and PNC over $24 \mathrm{~h}$ in a location adjacent to three main traffic roads in Seoul, Korea. The PNC was measured in the range of 0.3 to $10 \mu \mathrm{m}$. The noise data was measured by utilizing both the overall levels and spectral characteristics. Traffic data including volumes and speeds of vehicles on the roads were also collected. The results showed that the correlations among the three key parameters varied depending on changes in the noise frequency and particle size. The noise levels at $100-200 \mathrm{~Hz}$ were positively correlated with traffic volume and submicron particles. In contrast, they exhibited inverse correlations with the traffic speed and the number of larger particles $(>2.5 \mu \mathrm{m})$. Compared to noise levels at $100-200 \mathrm{~Hz}$, noise levels at $1-2 \mathrm{kHz}$ exhibited reverse relationships between the traffic and PNC. Submicron particles $(0.3-1.0 \mu \mathrm{m})$ tended to be more strongly associated with noise levels during the daytime, while those greater than $2.5 \mu \mathrm{m}$ maintained relatively stable correlations with the noise throughout the day. The findings address the importance of temporal and spectral-specific monitoring of air and noise pollutants for a better understanding of the exposure of the community to air and noise pollution.
\end{abstract}

Keywords: noise pollution; air pollution; particle number concentration; traffic; diurnal pattern; urban built environment

\section{Introduction}

Urban dwellers are exposed to multiple pollutants such as noise, light, and air pollutants; the exposure to combined environmental pollutants could increase the risk of adverse effects on human health and well-being [1]. Among the pollutants, as verified by extensive evidence, noise [2,3] and air [4,5] pollutions adversely affect human health. Epidemiological studies have demonstrated convincing associations between particulate air pollution and human health problems including cardiovascular, and respiratory diseases [4-8]. In particular, particulate pollutants, which consist of a heterogeneous mixture of particles suspended in air characterized by particulate matter (PM) and the particle number concentration (PNC), are associated with adverse human health effects [4,8-14].

Environmental noises are also known to potentially cause not only noise-induced hearing impairment $[3,15]$, but also non-auditory health problems [16]. Apart from hearing impairment, noise exposures have physiological effects such as mental stress, cardiovascular problems, and effect over the sense of balance $[17,18]$. Acute noise exposures can increase blood pressure, heart rate, 
and vasoconstriction by activating the autonomic and hormonal systems [16,19]. Chronic noise exposure can potentially cause hypertension and heart disease in vulnerable individuals [20-23]. Additionally, environmental noise causes annoyance, speech interference, sleep disturbance, and reduced performance of cognitive tasks in living spaces [21,24-31]. Perceived acoustic quality are also closely associated with mental health outcomes (e.g., psychological distress, incidence of anxiety, and depression) [32]. Accordingly, WHO Regional Office of Europe provides recommendations for protecting human health from exposure to environmental noise from various sources: transportation, wind turbine, and recreation [2].

In urban settings, vehicular traffic activities play an important role as a common source of both noise and air pollution [6,33-35]. There have been a number of studies investigating the relationships between environmental noise and air pollutants in urban areas [23,36-42]. Some studies have investigated the temporal correlations between air pollution and noise levels $[40,42,43]$. The temporal patterns of air pollutants including the mass/number concentrations of particulate matter and/or organic/inorganic compounds have been investigated in many previous studies to determine their associations with noise levels [40,42-45].

In terms of particulate pollutants, the particle mass fractions PM 10 and PM 2.5 are widely used. Although the PNC is not typically regulated, recent studies showed that the PNC associated with traffic conditions can be a significant indicator for health problems [11,12,46-48]. Nonetheless, relatively little is known about the temporal relationship between the PNC and noise $[43,49]$. In many previous studies, noise and air pollution data were usually monitored at distant locations, which may have complicated the interpretation of the relationships between noise, air pollution, and traffic.

In addition, regarding noise metrics, studies investigating the relationships between noise and air pollutions primarily adopted equivalent noise levels representing the overall level of noise to examine the association with air pollution $[37,43,47]$. Despite the fact that the spectral variation of traffic noise varies depending on traffic speeds and the type of vehicles [50,51], only a few studies have dealt with noise parameters while investigating the frequency characteristics of noise to explore the relationships with air pollution $[42,44,45]$.

In this context, the aims of this study are to explore the temporal correlations between traffic, noise, the PNC in urban areas, and to assess noise spectra indicators related to the particle size distribution to account for the status of air pollution. To achieve these goals, the noise conditions and PNC for various particle size fractions were measured concurrently in Seoul, Korea.

\section{Methods}

\subsection{Measurement Location}

The measurement location and neighboring geographical conditions are illustrated in Figure 1. The measurement of both noise and particle number was performed on a deck on the second floor of the Civil Engineering Building at Hanyang University, Seoul, Korea. The measurement unit was approximately $10 \mathrm{~m}$ above ground. The measurement site was exposed to air and noise pollutants from representative urban transportation systems including, different sizes of road sections and a metro lane. As shown in Figure 1, the measurement location is surrounded by three main road sections (T1-3) and one metro railway lane (M). The Sageundong road section, T1 (four lanes) and Wangsimni road section, T2 (six lanes), are $36 \mathrm{~m}$ and $42 \mathrm{~m}$ away from the measurement unit, respectively. The Dongbu Expressway road section, T3 (10 lanes), an expressway, runs nearly parallel to the measurement unit and the distance between the measurement unit and T3 was approximately $330 \mathrm{~m}$. There is a city stream, namely Joong-rang Cheon, between T3 and the measurement point. Additionally, the metro lane (M), which runs parallel to T2, is immediately adjacent to the measurement unit. According to the Seoul Metro, subway trains utilizing normal braking and regenerative braking operate on the metro lane. On average, five subway trains run per minute. Although the metro trains run on electricity, which does not generate as much pollution as road traffic, brake pad wear can be a particulate matter 
generator [44]. Other sources (e.g., industrial facilities) for noise and air pollutants were not located near the study area.

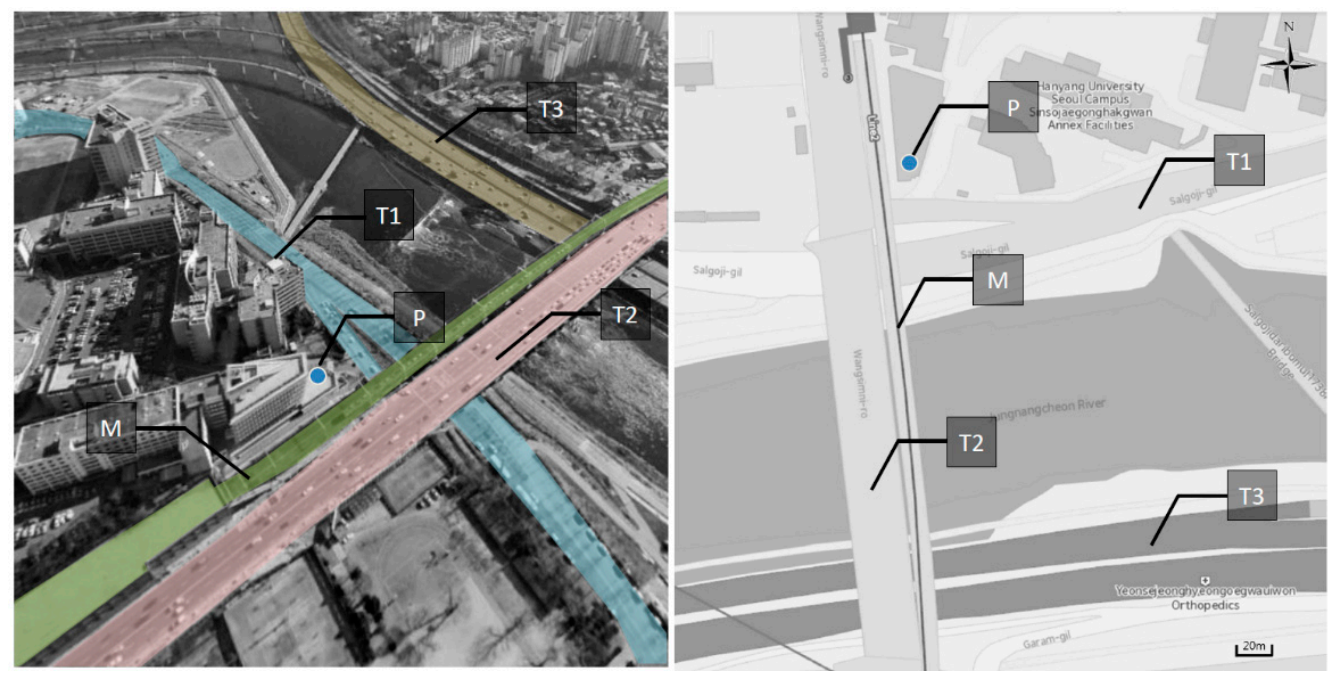

Figure 1. Field measurement area and traffic conditions (source: http:/ / map.naver.com). (a) Birdseye view and (b) aerial map of the measurement location. ' $\mathrm{T}$ ', ' $\mathrm{M}$ ', and ' $\mathrm{P}$ ' indicate the traffic road, metro lane, and measurement unit, respectively. T1 (four lanes), T2 (six lanes), and T3 (ten lanes) are $36 \mathrm{~m}, 42$ $\mathrm{m}, 330 \mathrm{~m}$ away from the measurement unit, respectively. $\mathrm{M}$ (two lanes) is immediately adjacent to the measurement unit.

\subsection{Measurement Equipment and Setup}

Figure 2 shows the measurement devices and set-up on the site. The environmental noise, mainly from road traffic, was measured using a type 2 sound level meter (SVAN 953, Svantek, Warsaw, Poland) according to ISO 1996-2 [52]. The sound level meter (SLM) was mounted on a tripod at a height of $1.5 \mathrm{~m}$ and the microphone of the SLM was covered by a windscreen. Total particle size distributions were measured using a Class I laser-based handheld airborne particle counter (AeroTrak APC-9306, TSI Inc., Shoreview, MN, USA). The particle counter was located at the same height of the SLM. The measurement of noise levels and PNC was conducted on Tuesday 18:00 8th-Wednesday 18:00 9th December 2015 (24 h) under clear weather. The noise levels and airborne particle counter data were logged with a step of $10 \mathrm{~s}$ and averaged every 5-min.
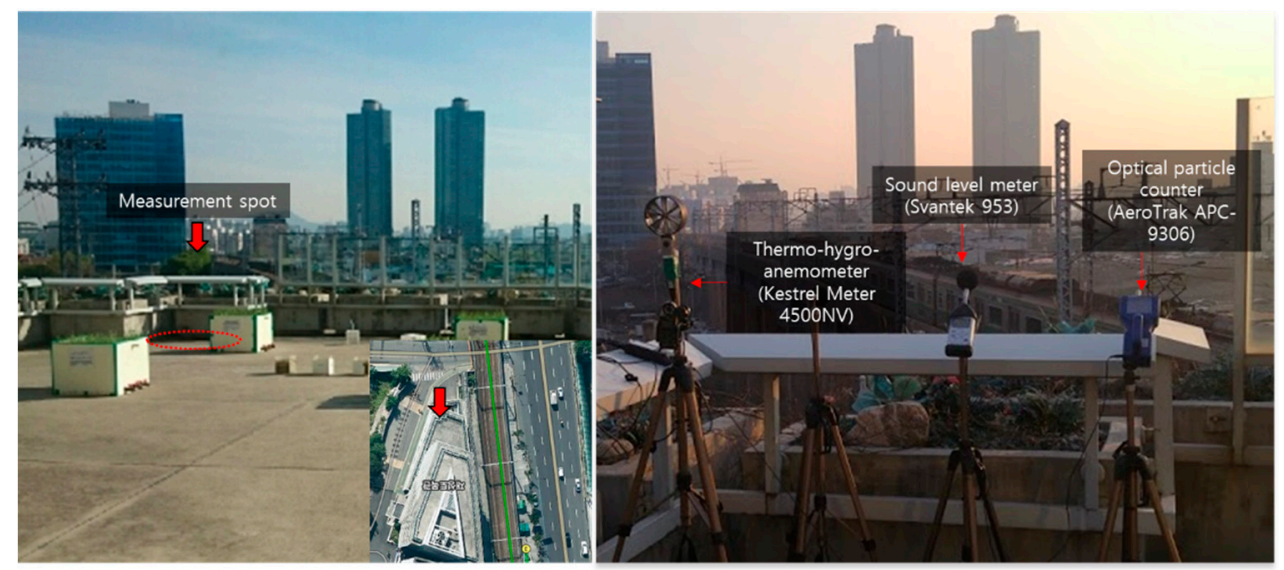

Figure 2. Measurement spot (left) and the recording set-up (right) on the site.

In the same manner, meteorological data, including the wind speed, temperature, and relative humidity (RH), which have been commonly measured in related studies, were simultaneously collected 
every $10 \mathrm{~s}$ using a portable thermo-hygro-anemometer (Kestrel Meter 4500NV, Kestrel Instruments, Boothwyn, PA USA), and the data were averaged every 5-min for analysis. In addition, during the sampling period, traffic from the three main traffic roads (T1-3) were recorded using video camcorders to calculate traffic volumes. Using the video recording, the hourly traffic volume of light and heavy vehicles were counted for each traffic road.

\subsection{Indicators for Noise, Particle Numbers, and Traffic}

Various noise indicators describing the sound pressure level as well as the spectral and temporal structure of the noise were calculated in this study. Unweighted noise levels were used to calculate the noise parameters in this study because unweighted noise levels exhibit stronger correlations with traffic and air pollution than A-weighted noise levels [42]. The equivalent sound pressure level $\left(L_{\text {eq }}\right)$ was calculated to describe the overall noise level. Percentile sound pressure levels including $L_{10}$, $L_{50}$, and $L_{90}$ were used to describe the temporal characteristics of the noise. In terms of the spectral characteristics of traffic noise, three noise parameters, $L_{\mathrm{OLF}}, L_{\mathrm{HLF}}$, and $L_{\mathrm{HF}-\mathrm{LF}}$, were employed to describe the noise emission from road vehicles based on the noise measurements in the one-third octave band spectra from a previous study [44]. $L_{\mathrm{OLF}}$ is the sum of the 100 to $200 \mathrm{~Hz}$ one-third octave band, which is developed to access the engine noise of road vehicles because in general, engine noise is dominant at low frequencies. $L_{\mathrm{HLF}}$, calculated as the sum from $1 \mathrm{kHz}$ to $2 \mathrm{kHz}$, is related to rolling noise, which contains higher energy at high frequencies and higher speeds. $L_{\mathrm{HF}-\mathrm{LF}}$ is the difference between $L_{\mathrm{HLF}}$ and $L_{\mathrm{OLF}}$, representing the high frequency content of noise.

In terms of air pollutants, the optical particle counter utilized for this measurement enabled us to monitor size-segregated PNCs ranging from 0.3 to $>10 \mu \mathrm{m}$ with six different particle sizes during the sampling period. The particle sizes of the PNCs were divided into six different size ranges of $0.3-0.5,0.5-1.0,1.0-2.5,2.5-5.0 \mu \mathrm{m}, 5.0-10.0 \mu \mathrm{m}$, and $>10.0 \mu \mathrm{m}$, similar to a previous study [53]. The traffic volume data aggregated by the number of vehicles per hour was calculated based on the video recordings during the measurement period. The hourly line-specific traffic density data was considered for both road directions of each road. The internet-posted traffic speed for each road section during the measurement period on the website of the urban traffic information system of Korea (www.utis.go.kr) were utilized.

\subsection{Data Analysis}

In order to explore the relationship among the noise, PNC, and traffic metrics, Pearson's correlation coefficients and multiple linear regression analyses were conducted. Based on the measured data, values averaged for $5 \mathrm{~min}$ over the sampling period were used to calculate the correlation coefficients among the noise parameters, PNC, and meteorological conditions. Meanwhile, the correlations with traffic parameters were analyzed using hourly data. All statistical analyses in this study were performed using the SPSS version 19.0 software. Since the hourly traffic speed and volume were collected from traffic roads (T1-3), the hourly averaged data with the corresponding standard deviations for noise indicators, PNCs, and meteorological parameters were plotted to compare with the temporal patterns of the traffic metrics.

\section{Results}

\subsection{Temporal Patterns of the Noise Levels}

The noise level data measured over $24 \mathrm{~h}$ is shown in Figure 3. The measured $L_{\text {eq }}$ ranged from $69.5 \mathrm{~dB}$ and $94.5 \mathrm{~dB}$ throughout the day where the mean $L_{\mathrm{eq}}$ was $79.4 \mathrm{~dB}$. The diurnal patterns of $L_{\mathrm{eq}}$ and percentile levels including $L_{10}, L_{50}$, and $L_{90}$ for the measurement period are illustrated in Figure $3 a$ to understand the temporal trends of the noise levels each hour. The temporal patterns of the noise indicators can be divided into three main periods (Period $1=07: 00-19: 00$, Period $2=19: 00-22: 00$, Period $3=22: 00-07: 00)$. The divided time periods correspond to the daytime, evening, and night 
according to the European Environmental Agency (EEA). Table 1 summarizes the measured noise indicators across three measurement periods.

Significant changes of the SPLs were found in Periods 1 and 2. Overall, the $L_{\text {eq }}$ values dramatically increased after 07:00 due to the rush traffic period and reached $90.0 \mathrm{~dB}$ at 13:00, while the noise levels began to decrease to $80.2 \mathrm{~dB}$ between 13:00 to 15:00. Regarding the temporal variability of noise environment in Period 1, the differences among the percentile noise levels gradually increased such that the mean $L_{10}-L_{90}$ value was approximately $12.1 \mathrm{~dB}$. Those findings imply that pronounced traffic activities may produce not only high noise levels but also various intrusive sound events such as car horns during Period 1, which are normally considered to be working hours. In addition, it was observed that $L_{\mathrm{eq}}$ precipitously increased after 15:00 and peaked at 18:00 with a value $90.7 \mathrm{~dB}$ due to the evening rush period. After working hours (Period 2), both overall noise level and temporal variance rapidly declined.

In contrast to the tendencies in Periods 1 and 2, there are moderate changes in the sound pressure levels (SPLs). Overall, $L_{\mathrm{eq}}$ was $72.6 \mathrm{~dB}(\mathrm{SD}=1.7 \mathrm{~dB})$ in Period 3, where the variance of the SPLs reached a steady state compared to the other periods. With regards to the temporal structure of noises, the difference between the $L_{10}$ and $L_{90}$ values in Period 3 was relatively smaller than the other periods with a value of approximately $5.5 \mathrm{~dB}$. This reflects that the traffic volume was constant with few noise sources excluding traffic such as human activities.

Figure $3 \mathrm{~b}$ shows the temporal patterns of the SPLs in a $1 / 3$ octave band from $63 \mathrm{~Hz}$ to $2 \mathrm{kHz}$. The diurnal trends of the SPLs band were different across the frequency band. It was found that high frequencies over $1 \mathrm{kHz}$ showed moderate changes over the measurement period. The $L_{\text {eq }}$ values at $1 \mathrm{kHz}$ and $2 \mathrm{kHz}$ remained stable between $55 \mathrm{~dB}$ and $60 \mathrm{~dB}$ for the sample period. Unlike high frequencies, the variations of the SPLs at low frequencies below $250 \mathrm{~Hz}$ were greater than those at high frequencies. Significant increments of the SPLs at low frequencies $(63-250 \mathrm{~Hz})$ were observed in Periods 1 and 2, whereas the SPLs were relatively constant in Period 3.

Table 1. Summary of the noise parameters across the measurement periods. Period 1= 07:00-19:00, Period 2 = 19:00-23:00, Period 3 = 23:00-07:00.

\begin{tabular}{ccccccccc}
\hline & & \multicolumn{7}{c}{ Noise Parameters [dB] } \\
\hline Period & & $\boldsymbol{L}_{\mathbf{e q}}$ & $\mathbf{L}_{\mathbf{9 0}}$ & $\boldsymbol{L}_{\mathbf{5 0}}$ & $\boldsymbol{L}_{\mathbf{1 0}}$ & $\boldsymbol{L}_{\mathbf{O L F}}$ & $\boldsymbol{L}_{\mathbf{H L F}}$ & $\boldsymbol{L}_{\text {HF-LF }}$ \\
\hline P1 & Mean & 83.5 & 74.4 & 79.2 & 86.5 & 68.2 & 61.0 & -7.2 \\
& Min & 73.6 & 70.4 & 73.5 & 75.5 & 60.4 & 58.7 & -13.9 \\
& Max & 94.5 & 81.1 & 88.9 & 98.3 & 73.7 & 63.8 & 1.9 \\
& SD & 5.8 & 2.1 & 4.0 & 6.2 & 2.5 & 1.0 & 2.9 \\
\hline P2 & Mean & 80.9 & 72.8 & 77.1 & 84.0 & 68.6 & 60.8 & -7.8 \\
& Min & 74.9 & 70.2 & 72.8 & 77.1 & 64.1 & 59.0 & -11.3 \\
& Max & 89.1 & 76.2 & 82.6 & 92.3 & 71.8 & 62.6 & -2.7 \\
& SD & 3.3 & 1.3 & 2.0 & 3.5 & 1.9 & 1.0 & 1.9 \\
\hline P3 & Mean & 72.6 & 69.2 & 71.5 & 74.7 & 61.4 & 62.3 & 0.9 \\
& Min & 69.5 & 66.5 & 68.1 & 70.9 & 55.6 & 59.8 & -9.1 \\
& Max & 79.9 & 72.6 & 76.3 & 83.4 & 71.2 & 64.1 & 7.8 \\
& SD & 1.7 & 1.3 & 1.5 & 2.0 & 4.1 & 1.0 & 4.2 \\
\hline \multirow{2}{*}{ Total } & Mean & 79.4 & 72.4 & 76.3 & 82.1 & 66.0 & 61.4 & -4.6 \\
& Min & 69.5 & 66.5 & 68.1 & 70.9 & 55.6 & 58.7 & -13.9 \\
& Max & 94.5 & 81.1 & 88.9 & 98.3 & 73.7 & 64.1 & 7.8 \\
& SD & 6.6 & 2.9 & 4.6 & 7.2 & 4.5 & 1.2 & 5.1 \\
\hline
\end{tabular}



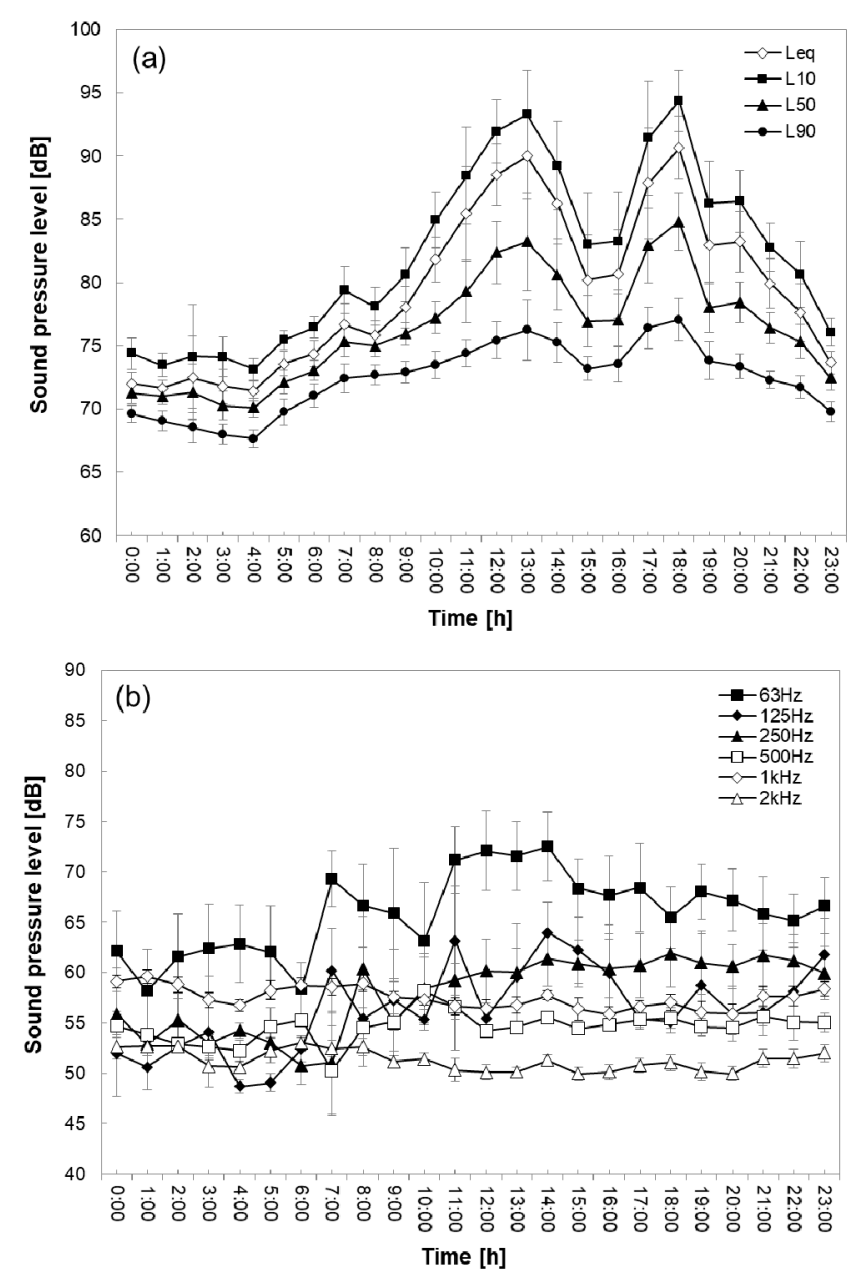

Figure 3. Temporal patterns of the SPLs: (a) $L_{\mathrm{eq}}$ and percentile levels and (b) spectral characteristics of noises. The error bars indicate standard deviations.

\subsection{Temporal Patterns of Road Traffic Data}

The temporal variation in traffic volume (vehicle/hour, $\mathrm{v} / \mathrm{h}$ ) over the measurement period from three different road sections and the metro lane are plotted in Figure 4. According to the Korea highway traffic noise prediction model (KHTN), the vehicles were classified into two types: heavy (gross vehicle weight $\geq 2.5 \mathrm{t}$ ) and light (gross vehicle weight $<2.5 \mathrm{t}$ ) vehicles. As shown in Table 2, the percentages of light and heavy vehicle types for the three road sections were similar across the measurement period. The proportion of light vehicles was more than seven times higher than that of heavy vehicles across the three road sections. The standard deviations of the traffic volumes of light and heavy vehicles for $\mathrm{T} 1$ and $\mathrm{T} 2$ were approximately $6 \%$, while that for $\mathrm{T} 3$ was approximately $4 \%$, indicating that the proportions of light and heavy vehicle types for the three road sections were consistent across the measurement period.

Table 2. Percentages of vehicle types on the three road sections over the measurement period.

\begin{tabular}{ccccccc}
\hline Road & \multicolumn{2}{c}{ T1 } & \multicolumn{2}{c}{ T2 } & \multicolumn{2}{c}{ T3 } \\
\hline Vehicle Type & Light & Heavy & Light & Heavy & Light & Heavy \\
\hline Mean & $88.0 \%$ & $12.0 \%$ & $89.9 \%$ & $10.1 \%$ & $92.6 \%$ & $7.4 \%$ \\
SD & $6.3 \%$ & $6.6 \%$ & $6.2 \%$ & $6.4 \%$ & $3.5 \%$ & $3.9 \%$ \\
\hline
\end{tabular}



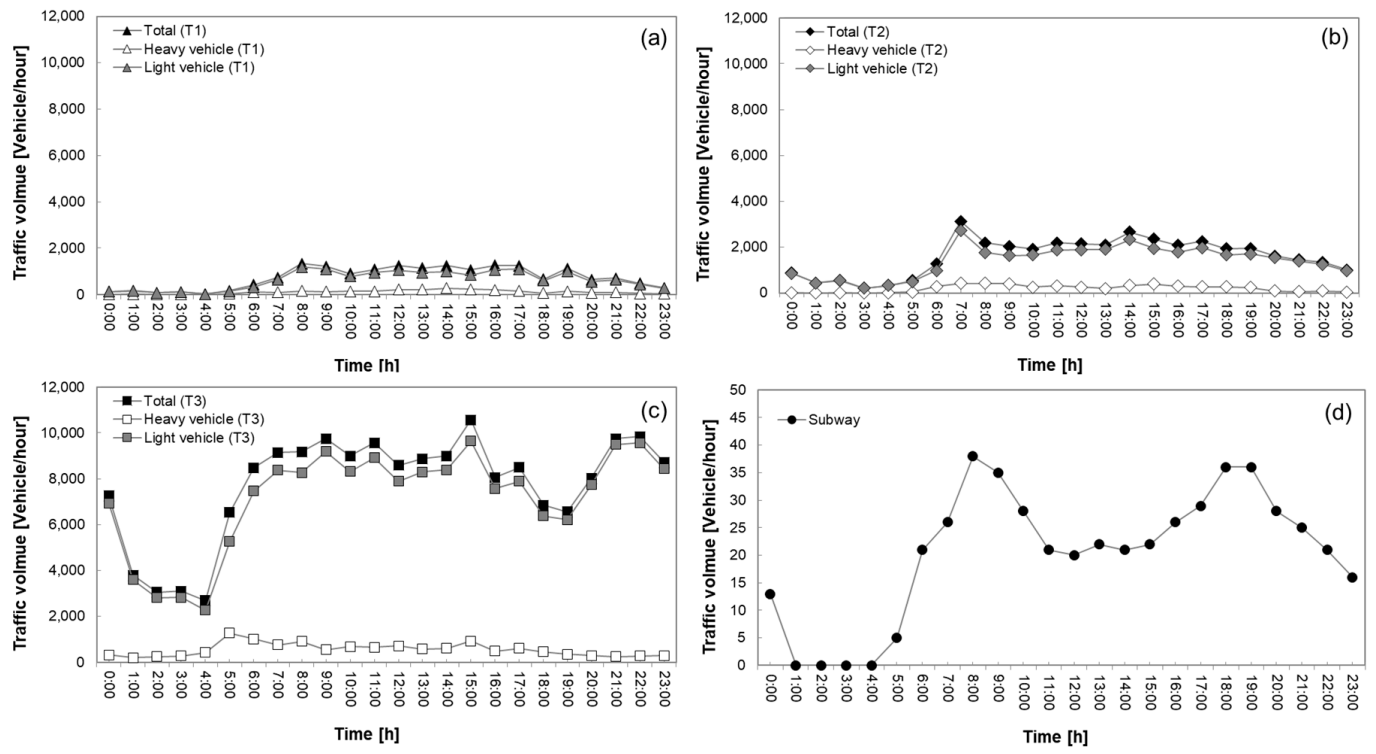

Figure 4. Temporal patterns of the traffic volume: (a) T1, (b) T2 (c) T3 and (d) Subway train.

Table 3 shows the measured traffic indicators across three measurement periods. The total traffic volume on the expressway, namely T3 (mean $=7701.0, \mathrm{SD}=2320.1$ ), was approximately 10.6 and 4.8 times greater than that on $\mathrm{T} 1($ mean $=726.0 \mathrm{v} / \mathrm{h}, \mathrm{SD}=464.7 \mathrm{v} / \mathrm{h})$ and T2 $(\mathrm{mean}=1607.5 \mathrm{v} / \mathrm{h}$, $\mathrm{SD}=795.9 \mathrm{v} / \mathrm{h})$, respectively. The road traffic parameters can also be explained by the three time periods (Periods 1-3) defined in the noise measurement data.

Table 3. Summary of vehicle types on the three road sections over the measurement period. Period $1=$ 07:00-19:00, Period $2=19: 00-23: 00$, Period $3=23: 00-07: 00$.

\begin{tabular}{cccccccc}
\hline & Road & \multicolumn{2}{c}{ T1 } & \multicolumn{3}{c}{ T2 } & T3 \\
\hline Period & Vehicle Type & Light & Heavy & Light & Heavy & Light & Heavy \\
\hline P1 & Sum & 464 & 16 & 2377 & 47 & 18,440 & 1432 \\
& Min & 12 & 0 & 212 & 0 & 2270 & 195 \\
& Max & 156 & 12 & 856 & 20 & 6934 & 418 \\
& Mean & 92.8 & 3.2 & 475.4 & 9.4 & 3688.0 & 286.4 \\
& SD & 55.0 & 5.2 & 245.1 & 8.4 & 1875.1 & 85.3 \\
\hline P2 & Sum & 8888 & 1660 & 19,206 & 3318 & 90,031 & 8633 \\
& Min & 137 & 31 & 493 & 47 & 5263 & 550 \\
& Max & 1184 & 265 & 2716 & 416 & 9650 & 1265 \\
& Mean & 808.0 & 150.9 & 1746.0 & 301.6 & 8184.6 & 784.8 \\
& SD & 327.5 & 68.0 & 595.5 & 113.7 & 1138.6 & 221.1 \\
\hline \multirow{2}{*}{ P3 } & Sum & 5612 & 784 & 12,295 & 1337 & 63,293 & 2995 \\
& Min & 262 & 26 & 971 & 37 & 6209 & 249 \\
& Max & 1085 & 194 & 1972 & 300 & 9573 & 609 \\
& Mean & 701.5 & 98.0 & 1536.9 & 167.1 & 7911.6 & 374.4 \\
& SD & 309.3 & 56.8 & 319.8 & 110.9 & 1248.6 & 128.6 \\
\hline \multirow{2}{*}{ Total } & Sum & 14,964 & 2460 & 33,878 & 4702 & 171,764 & 13,060 \\
& Min & 12 & 0 & 212 & 0 & 2270 & 195 \\
& Max & 1184 & 265 & 2716 & 416 & 9650 & 1265 \\
& Mean & 623.5 & 102.5 & 1411.6 & 195.9 & 7156.8 & 544.2 \\
& SD & 394.8 & 79.2 & 667.3 & 150.2 & 2229.1 & 282.4 \\
\hline
\end{tabular}

As shown in Figure $4 a-c$, the traffic volume significantly increased starting at 6:00 and peaked from 7:00-09:00 for T1 $(1212 \mathrm{v} / \mathrm{h}), \mathrm{T} 2(2040 \mathrm{v} / \mathrm{h})$, and T3 $(9744 \mathrm{v} / \mathrm{h})$ because of the morning traffic rush. During main working hours (Period 1), the traffic volumes on T1 and T2 were constant but that on 
T3 fluctuated slightly and decreased from 15:00-18:00. In Period 2, the traffic on T1 and T2 gradually declined, while the traffic volume on T3 increased again after the evening rush period. Peak hour traffic volumes in the afternoon for T1-3 were 10,572 v/h, $1248 \mathrm{v} / \mathrm{h}$, and $2652 \mathrm{v} / \mathrm{h}$, respectively. In Period 3, the traffic volume on $\mathrm{T} 1$ dramatically decreased just after midnight and remained the lowest from 1:00 to 4:00 for all of the traffic roads. The traffic volumes on T1 and T2 during Period 3 were also the smallest over the sampling period. As shown in Figure 4d, the traffic related to the subway train was much smaller than that on the three main road sections. The subway operation hours in Seoul are from 5:30 to approximately 24:00 and the number of subway trains passing by the measurement location varied depending on the time of the day. The number of trains gradually increased from 6:00 until peaking at 8:00-9:00 based on the morning rush, then decreased from 10:00-12:00 before peaking again at the evening rush from 19:00-20:00.

The temporal variations in traffic speed for each road section are plotted in Figure 5. The traffic speed data per hour for the three main road sections during the sampling period were collected from a website provided by the urban traffic information system of Korea (www.utis.go.kr). The mean traffic speed on T3 over the sampling period was $77.9 \mathrm{~km} / \mathrm{h}$, while those on T1 and T2 were relatively slow with values of $25.3 \mathrm{~km} / \mathrm{h}$ and $37.4 \mathrm{~km} / \mathrm{h}$, respectively. The temporal variance of the traffic speed on T3 $(\mathrm{SD}=4.2 \mathrm{~km} / \mathrm{h})$ was relatively smaller than those on T1 $(\mathrm{SD}=6.8 \mathrm{~km} / \mathrm{h})$ and T2 $(\mathrm{SD}=6.4 \mathrm{~km} / \mathrm{h})$.

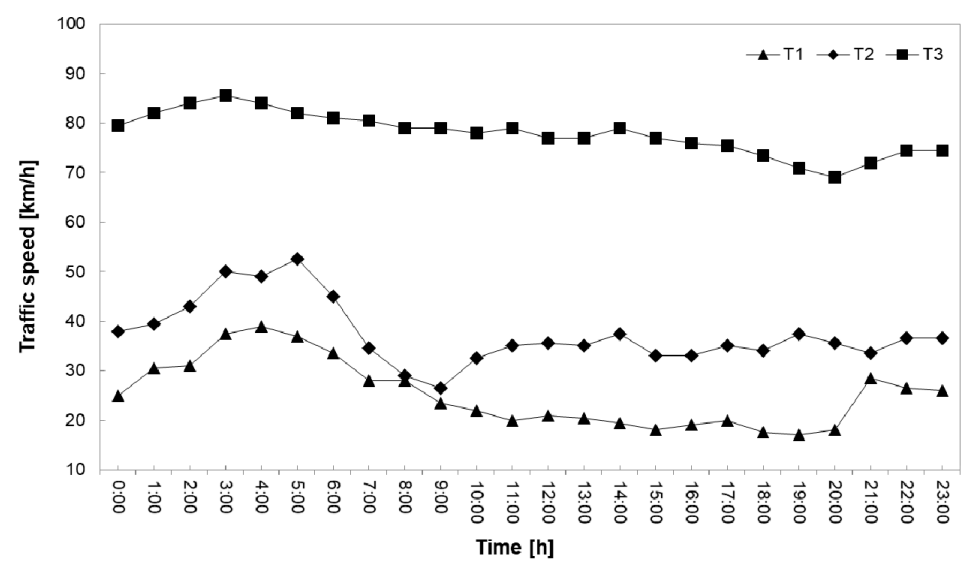

Figure 5. Temporal patterns of the traffic speed.

In Period 1, the traffic speed on T2 decreased significantly from $45.0 \mathrm{~km} / \mathrm{h}$ to $23.5 \mathrm{~km} / \mathrm{h}$ due to the morning rush (06:00-09:00) and almost constant traffic speeds were recorded with a value of approximately $34.3 \mathrm{~km} / \mathrm{h}$. The traffic speed on T3 showed a similar temporal tendency with that on T2 during the period of 09:00-20:00, while a sudden increment of the traffic speed was observed during Period 2 (20:00-21:00). In general, the traffic speeds in Period 3 were higher than the other periods for all of the traffic roads.

\subsection{Temporal Patterns of the Particle Concentration and Meteorological Data}

The particle number size distributions in six size ranges $(0.3$ to $>10 \mu \mathrm{m})$ were collected during the measurement period as shown in Table 4. The hourly averaged values of the particle number sizes are shown in Figure 6. It was found that the diurnal tendencies of the measured PNC were different depending on the particle size. In general, there are two temporal patterns for the particle sizes. Smaller particles between 0.3 and $1.0 \mu \mathrm{m}$ tended to decrease during the periods of 0:00-02:00 and 21:00-23:00 and tended to peak around noon (11:00-12:00). In contrast to the smaller particles, the larger particles from 2.5 to $>10.0 \mu \mathrm{m}$ gradually declined during the working hours before peaking at midnight and then tended to slightly increase in the night time. 
Table 4. Summary of the particle number size distributions across the measurement periods. Period 1 = 07:00-19:00, Period 2 = 19:00-23:00, Period 3 = 23:00-07:00.

\begin{tabular}{cccccccc}
\hline \multicolumn{7}{c}{ Particle Number Size Ranges $[\boldsymbol{\mu m}]$} \\
\hline Period & & $\mathbf{0 . 3 - 0 . 5}$ & $\mathbf{0 . 5 - 1 . 0}$ & $\mathbf{1 . 0 - 2 . 5}$ & $\mathbf{2 . 5 - 5 . 0}$ & $\mathbf{5 . 0 - 1 0 . 0}$ & $>\mathbf{1 0 . 0}$ \\
\hline P1 & Mean & 197,966 & 24,725 & 1,642 & 108 & 50 & 9 \\
& Min & 175,560 & 21,208 & 1,365 & 86 & 36 & 6 \\
& Max & 216,635 & 27,992 & 1,934 & 140 & 70 & 15 \\
& SD & 9427 & 1574 & 136 & 9 & 7 & 2 \\
\hline P2 & Mean & 179,809 & 23,593 & 1,339 & 111 & 57 & 11 \\
& Min & 149,664 & 20,829 & 1,157 & 93 & 44 & 8 \\
& Max & 206,362 & 27,531 & 1,758 & 152 & 84 & 16 \\
& SD & 16,328 & 1761 & 145 & 14 & 9 & 2 \\
\hline P3 & Mean & 174,314 & 22,045 & 1,651 & 137 & 71 & 13 \\
& Min & 147,226 & 17,939 & 1,198 & 101 & 52 & 9 \\
& Max & 206,081 & 26,070 & 2,073 & 235 & 132 & 27 \\
& SD & 17,885 & 2511 & 186 & 22 & 15 & 3 \\
\hline \multirow{2}{*}{ Total } & Mean & 187,056 & 23,643 & 1,594 & 118 & 58 & 11 \\
& Min & 147,226 & 17,939 & 1,157 & 86 & 36 & 6 \\
& Max & 216,635 & 27,992 & 2,073 & 235 & 132 & 27 \\
& SD & 17,794 & 2296 & 193 & 20 & 14 & 3 \\
\hline
\end{tabular}
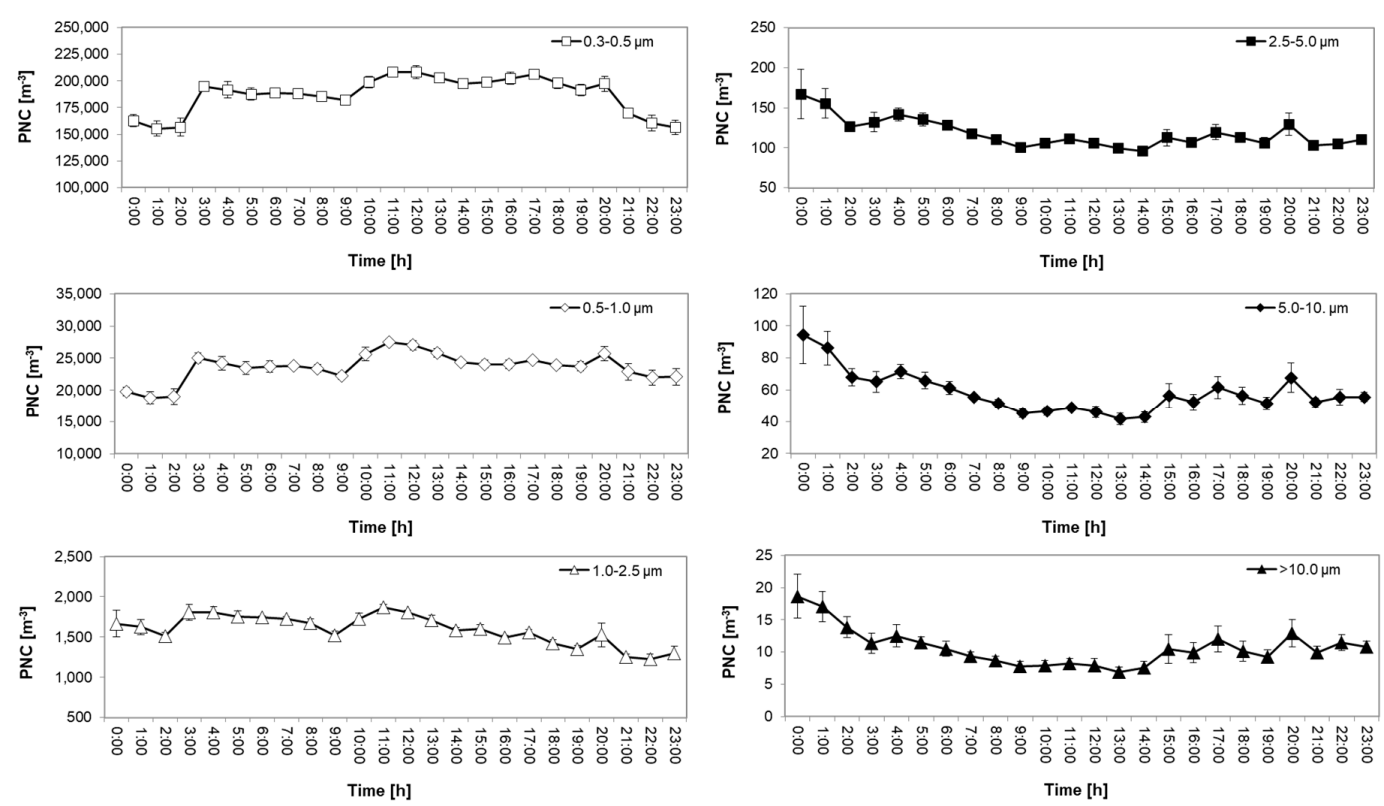

Figure 6. Temporal patterns of the particle number concentrations. The error bars indicate the standard deviations.

Table 5 presents the measured meteorological indicators across three measurement periods. During the sampling period, the ambient temperature was almost constant in the range from 5.0 to $6.1^{\circ} \mathrm{C}$ (mean $=5.2^{\circ} \mathrm{C}, \mathrm{SD}=0.3^{\circ} \mathrm{C}$ ) as shown in Figure $7 \mathrm{a}$. The wind speed showed small variations ranging from $0.0-0.5 \mathrm{~m} / \mathrm{s}$, as plotted in Figure $7 \mathrm{~b}$. Additionally, there was no wind during the measurement period of 12:00-22:00. According to the Beaufort wind-force scale [47], the wind speed (mean $=0.2 \mathrm{~m} / \mathrm{s}, \mathrm{SD}=0.2 \mathrm{~m} / \mathrm{s}$ ) across the measurement period can be described as calm. RH showed large variation during the measurement period as shown in Figure 7c. In Period 1, RH decreased from $54.4 \%$ to $39.6 \%$. During period 1 and 2, RH gradually increased by $58.5 \%$. 
Table 5. Summary of the meteorological indicators across the measurement periods. Period 1 $=$ 07:00-19:00, Period 2 = 19:00-23:00, Period 3 = 23:00-07:00.

\begin{tabular}{ccccc}
\hline Period & & Wind Speed $[\mathbf{m} / \mathbf{s}]$ & Temp. $\left[{ }^{\circ} \mathbf{C}\right]$ & RH [\%] \\
\hline P1 & Mean & 0.1 & 5.3 & 41.1 \\
& Min & 0.0 & 5.0 & 30.8 \\
& Max & 0.6 & 6.6 & 58.0 \\
& SD & 0.2 & 0.4 & 6.0 \\
\hline P2 & Mean & 0.1 & 5.2 & 42.3 \\
& Min & 0.0 & 4.9 & 38.5 \\
& Max & 1.1 & 5.6 & 46.0 \\
& SD & 0.2 & 0.2 & 2.2 \\
\hline P3 & Mean & 0.4 & 5.1 & 52.8 \\
& Min & 0.0 & 4.9 & 45.1 \\
& Max & 0.6 & 5.1 & 61.0 \\
& SD & 0.2 & 0.1 & 4.3 \\
\hline Total & Mean & 0.2 & 5.2 & 45.2 \\
& Min & 0.0 & 4.9 & 30.8 \\
& Max & 1.1 & 6.6 & 7.0 \\
\hline
\end{tabular}
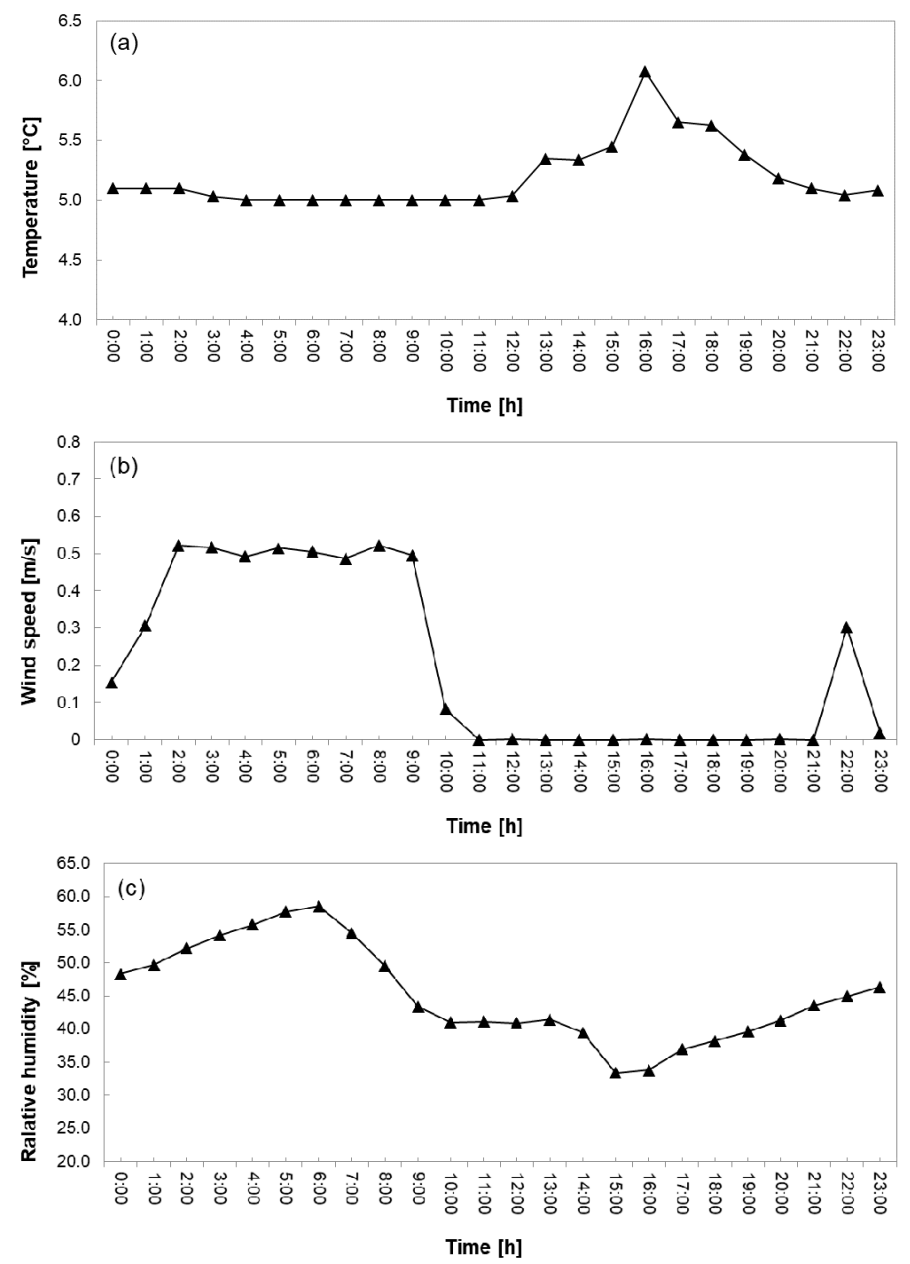

Figure 7. Temporal patterns of the meteorological conditions: (a) wind speed, (b) temperature, and (c) relative humidity. 


\subsection{Relationships between Noise Levels and Traffic Data}

Correlation analyses between the noise parameters and traffic data were conducted using the measured data. The correlation coefficients between the noise indicators and traffic volume for each road are presented in Table 6 according to the vehicle types. In addition, the correlation between the noise indicators and traffic speed are listed in Table 7. In general, there was a reverse relationship between the traffic volume and traffic speed. This indicates that the traffic speed tended to decrease as the traffic volume increased on a road due to traffic congestion.

Table 6. Correlation coefficients between the noise levels and traffic volume.

\begin{tabular}{|c|c|c|c|c|c|c|c|c|}
\hline Road & Vehicle Type & $L_{\mathrm{eq}}$ & $L_{90}$ & $L_{50}$ & $L_{10}$ & $L_{\mathrm{OLF}}$ & $L_{\mathrm{HLF}}$ & $L_{\text {HF-LF }}$ \\
\hline \multirow{3}{*}{$\mathrm{T} 1$} & Light & $0.72 * *$ & $0.82^{* *}$ & 0.74 ** & 0.72 ** & 0.79 ** & -0.51 * & -0.79 ** \\
\hline & Heavy & $0.71^{* *}$ & $0.77^{* *}$ & 0.70 ** & $0.70^{* *}$ & $0.70^{* *}$ & -0.49 * & $-0.71^{* *}$ \\
\hline & Total & $0.73^{* *}$ & $0.83^{* *}$ & $0.75^{* *}$ & $0.73^{* *}$ & $0.79 * *$ & -0.51 * & $-0.79 * *$ \\
\hline \multirow{3}{*}{$\mathrm{T} 2$} & Light & $0.72 * *$ & $0.83^{* *}$ & $0.75^{* *}$ & $0.72 * *$ & 0.75 ** & -0.39 & $-0.73^{* *}$ \\
\hline & Heavy & $0.48 *$ & $0.66^{* *}$ & $0.53 * *$ & $0.48 *$ & 0.54 ** & -0.24 & $-0.51 * *$ \\
\hline & Total & $0.69 * *$ & $0.82^{* *}$ & $0.73^{* *}$ & $0.70^{* *}$ & $0.73^{* *}$ & -0.38 & $-0.71^{* *}$ \\
\hline \multirow{3}{*}{$\mathrm{T} 3$} & Light & $0.49 *$ & $0.62^{* *}$ & $0.52 * *$ & 0.50 * & $0.76^{* *}$ & -0.22 & $-0.70 * *$ \\
\hline & Heavy & 0.10 & 0.22 & 0.13 & 0.09 & 0.04 & 0.05 & -0.02 \\
\hline & Total & $0.49 *$ & $0.63^{* *}$ & $0.53^{* *}$ & $0.50 *$ & $0.74^{* *}$ & -0.21 & $-0.67^{* *}$ \\
\hline Subway & Train & $0.62 * *$ & $0.77^{* *}$ & $0.67^{* *}$ & $0.63^{* *}$ & $0.75^{* *}$ & -0.36 & -0.72 ** \\
\hline
\end{tabular}

Table 7. Correlation coefficients between the noise levels and traffic speed.

\begin{tabular}{cccccccc}
\hline Road & $\boldsymbol{L}_{\mathrm{eq}}$ & $\boldsymbol{L}_{\mathbf{9 0}}$ & $\boldsymbol{L}_{\mathbf{5 0}}$ & $\boldsymbol{L}_{\mathbf{1 0}}$ & $\boldsymbol{L}_{\mathrm{OLF}}$ & $\boldsymbol{L}_{\mathrm{HLF}}$ & $\boldsymbol{L}_{\mathrm{HF}-\mathrm{LF}}$ \\
\hline $\mathrm{T} 1$ & $-0.80^{* *}$ & $-0.83^{* *}$ & $-0.80^{* *}$ & $-0.81^{* *}$ & $-0.80^{* *}$ & $0.60^{* *}$ & $0.81^{* *}$ \\
$\mathrm{~T} 2$ & $-0.50^{* *}$ & $-0.64^{* *}$ & $-0.55^{* *}$ & $-0.51^{* *}$ & $-0.68^{* *}$ & $0.24^{* *}$ & $0.63^{* *}$ \\
$\mathrm{~T} 3$ & $-0.59^{* *}$ & $-0.60^{* *}$ & $-0.59^{* *}$ & $-0.60^{* *}$ & $-0.72^{* *}$ & $0.52^{* *}$ & $0.73^{* *}$ \\
\hline \multicolumn{8}{c}{$p<0.05^{* *} p<0.01}$. \\
\end{tabular}

Overall, $L_{\text {eq }}$ is highly correlated with the traffic volume and traffic speed on $\mathrm{T} 1$ and $\mathrm{T} 2$, which are close to the measurement point, whereas $L_{\text {eq }}$ showed a relatively lower correlation with traffic on T3, which is more than $300 \mathrm{~m}$ from the measurement unit. Similarly, more significant correlations between the percentile levels and traffic parameters were found on T1 and T2 compared to T3. Among the percentile noise levels, $L_{90}$, closely related to the background noise level, showed the highest correlation with the traffic parameters across three traffic roads. The traffic volume of the subway exhibited similar correlation patterns with the noise indicators compared to road traffic, showing positive correlations with $L_{\mathrm{eq}}$ and $L_{\mathrm{OLF}}$, but negative correlation with $L_{\mathrm{HF}-\mathrm{LF}}$.

Regarding the vehicle types, the correlations for light vehicle volumes were generally greater than those for heavy vehicle volumes. This may be because the proportions of light vehicles were significantly larger than those of heavy vehicles across the three road sections, meaning the contributions of light vehicles to the variations in noise indicators may be more significant than those of heavy vehicles in the measurement locations for our study.

The spectral characteristics of noise were also associated with the traffic parameters. The $L_{\mathrm{OLF}}$ values representing low frequency levels generated from vehicle engines are positively correlated with traffic volumes, while a negative relationship was obtained for the traffic speed $(p<0.01)$. Conversely, the $L_{\mathrm{HLF}}$ values related to high frequencies from rolling noise showed statistically negative and positive correlations with the traffic volume and traffic speed, respectively, for all of the traffic roads. This can be explained because noise levels at low frequencies tend to increase with increasing traffic volume, which causes low vehicle speeds. On the contrary, increasing traffic speed may cause increased rolling noise, which is closely related to the SPLs in the range of $1-2 \mathrm{kHz}$. 
In particular, traffic data, such as volume and speed on T1, showed slightly stronger correlations with $L_{\mathrm{OLF}}$ compared to those on T2. This may be because lower traffic speeds on T1 (mean traffic: $25.3 \mathrm{~km} / \mathrm{h}$ ) lead to lower-frequency contributions compared to T2 (mean traffic: $37.4 \mathrm{~km} / \mathrm{h}$ ) because the noise of the tire/pavement interface typically dominates at $40 \mathrm{~km} / \mathrm{h}$ or greater [48]. The correlations between $L_{\mathrm{OLF}}$ and the traffic parameters were relatively stronger than those of $L_{\mathrm{HLF}}$. This may be because road traffic noise mainly consists of low frequency contents. The $L_{\mathrm{HF}-\mathrm{LF}}$ value, which represents the relative contribution of high frequency energy to low frequencies, was highly correlated with the traffic parameters. Although the mean traffic speed on T3 was high at approximately $80 \mathrm{~km} / \mathrm{h}$, which may contribute to noise above $1 \mathrm{kHz}$ being generated by the tire/pavement interface, the correlations between the traffic speed on T1 and high-frequency noise indicators ( $L_{\mathrm{HLF}}$ and $\left.L_{\mathrm{HF}-\mathrm{LF}}\right)$ were relatively stronger than those on T3. This can be explained by the fact that the contributions of T3 to $L_{\mathrm{HLF}}$ and $L_{\mathrm{HF}-\mathrm{LF}}$ may have been shielded by the nearby road T1, which dominated the noise indicators, because T3 was much farther away from the measurement location than the other road sections.

\subsection{Relationships between the PNC, Traffic Data, and Meteorological Data}

The correlation coefficients between the PNCs and traffic parameters (traffic volume and speed) are listed in Tables 8 and 9, respectively. Two major relationships were found in terms of particle size. Smaller particle sizes ranging from $0.3-1.0 \mu \mathrm{m}$ showed a strong positive correlation with the traffic volume on T1 and T2 for both light and heavy vehicles, whereas the correlation coefficients between submicron particles $(0.3-1.0 \mu \mathrm{m})$ and the traffic volumes on T3 and the subway lane were not significant. Statistically significant correlations were only found between the traffic volumes of heavy vehicles and particle sizes of $0.3-0.5 \mu \mathrm{m}(r=0.47, p<0.05)$ and 1.0-2.5 $\mu \mathrm{m}(r=0.50, p<0.05)$. Overall, statistically significant correlations were not observed between traffic speed and the concentration of smaller particles on the three road sections, except for particle sizes of $0.3-0.5 \mu \mathrm{m}$ on T3 $(r=-0.41$, $p<0.05)$. These findings indicate that the concentrations of submicron particles were significantly influenced by traffic volume on roads near the measurement unit. Statistically significant correlations were not found between particles with sizes of 1.0-2.5 $\mu \mathrm{m}$ and traffic parameters, except for the relationship with the traffic speed on T3 $(r=0.66, p<0.01)$.

Table 8. Correlation coefficients between the PNC and traffic volume.

\begin{tabular}{|c|c|c|c|c|c|c|c|}
\hline \multirow{2}{*}{ Road } & \multirow{2}{*}{ Vehicle Type } & \multicolumn{6}{|c|}{ Particle Size Range $[\mu \mathrm{m}]$} \\
\hline & & $0.3-0.5$ & $0.5-1.0$ & $1.0-2.5$ & $2.5-5.0$ & $5.0-10.0$ & $>10.0$ \\
\hline \multirow{3}{*}{$\mathrm{T} 1$} & Light & $0.60 * *$ & $0.52 * *$ & -0.05 & $-0.74^{* *}$ & $-0.74 * *$ & $-0.70^{* *}$ \\
\hline & Heavy & $0.65^{* *}$ & $0.56^{* *}$ & 0.08 & $-0.69 * *$ & $-0.72^{* *}$ & $-0.69^{* *}$ \\
\hline & Total & $0.62 * *$ & $0.54^{* *}$ & -0.03 & $-0.74^{* *}$ & $-0.75^{* *}$ & $-0.71^{* *}$ \\
\hline \multirow{3}{*}{$\mathrm{T} 2$} & Light & $0.53^{* *}$ & $0.49 *$ & -0.06 & $-0.68^{* *}$ & $-0.67^{* *}$ & $-0.63^{* *}$ \\
\hline & Heavy & $0.56^{* *}$ & $0.42 *$ & 0.16 & $-0.59 * *$ & $-0.64^{* *}$ & $-0.66^{* *}$ \\
\hline & Total & $0.55^{* *}$ & $0.49^{*}$ & -0.02 & $-0.68 * *$ & $-0.68^{* *}$ & $-0.65^{* *}$ \\
\hline \multirow{3}{*}{ T3 } & Light & 0.20 & 0.33 & -0.29 & $-0.64^{* *}$ & $-0.59 * *$ & $-0.51 *$ \\
\hline & Heavy & $0.47^{*}$ & 0.38 & $0.50 *$ & -0.15 & -0.30 & -0.40 \\
\hline & Total & 0.25 & 0.36 & -0.22 & $-0.63^{* *}$ & $-0.60 * *$ & $-0.54^{* *}$ \\
\hline Subway & Train & 0.38 & 0.36 & -0.33 & $-0.64^{* *}$ & $-0.60^{* *}$ & $-0.56^{* *}$ \\
\hline
\end{tabular}


Table 9. Correlation coefficients between the PNC and traffic speed.

\begin{tabular}{ccccccc}
\hline \multirow{2}{*}{ Road } & \multicolumn{7}{c}{ Particle Size Range $[\boldsymbol{\mu m}]$} \\
\cline { 2 - 7 } & $\mathbf{0 . 3 - 0 . 5}$ & $\mathbf{0 . 5 - 1 . 0}$ & $\mathbf{1 . 0 - 2 . 5}$ & $\mathbf{2 . 5 - 5 . 0}$ & $\mathbf{5 . 0 - 1 0 . 0}$ & $>\mathbf{1 0 . 0}$ \\
\hline T1 & $-0.41^{*}$ & -0.34 & 0.30 & $0.52^{* *}$ & $0.45^{*}$ & $0.35^{*}$ \\
T2 & -0.12 & -0.11 & 0.34 & $0.56^{* *}$ & $0.48^{*}$ & $0.39^{*}$ \\
T3 & -0.13 & -0.24 & $0.66^{* *}$ & $0.45^{*}$ & 0.33 & 0.22 \\
\hline \multicolumn{7}{c}{$p<0.05,{ }^{* *} p<0.01}$.
\end{tabular}

The PNC for particles larger than $2.5 \mu \mathrm{m}$ was more significantly correlated with traffic data including traffic volume and speed than smaller particle sizes of $0.3-1.0 \mu \mathrm{m}$. In contrast to submicron particle sizes, larger particle sizes $(2.5-10 \mu \mathrm{m})$ had negative correlations with traffic volumes for all three road sections and the subway lane. It was also found that the correlation of traffic volume increased as the distance from the measurement position decreased. The correlation strengths between particles larger than $2.5 \mu \mathrm{m}$ and traffic volume on $\mathrm{T} 1$ and $\mathrm{T} 2$ were relatively stronger than that on T3. This implies that the distance from the traffic road may be one of the factors that affects the PNC. In terms of vehicle types, the correlation coefficients for the light and heavy vehicle types on T1 and T2 were similar. Unlike T1 and T2, the traffic volume of light vehicles on T3 was significantly correlated to the PNCs $(2.5-10 \mu \mathrm{m})$, whereas that of heavy vehicles on T3 did not show any significant relationship with larger particle sizes $(2.5-10 \mu \mathrm{m})$.

In addition, positive relationships were also found between the number of larger particles $(>2.5 \mu \mathrm{m})$ and the traffic speed on T1 and T2, whereas the particles between 2.5 and $5.0 \mu \mathrm{m}$ only showed a statistically significant correlation with the traffic speed on T3. In particular, the correlation between the PNC and traffic speed decreased as the particle size increased. Among the larger particles, the particles with sizes of 2.5-5.0 $\mu \mathrm{m}$ were the most significantly correlated with traffic speed for all of the roads.

Table 10 presents the correlation coefficients between the PNC and meteorological conditions. Overall, the correlation strengths of meteorological parameters were weaker than those of the noise parameters. Wind speed and RH showed negative correlations with the PNC at $<1.0 \mu \mathrm{m}$, with a positive correlation with larger particle sizes $(>2.5 \mu \mathrm{m})$. In terms of temperature, negative relationships with the particle size $(1.0-10.0 \mu \mathrm{m})$ were found and the correlations with the PNC were weaker compared to those of the RH and wind speed.

Table 10. Correlation coefficients between the PNC and meteorological data.

\begin{tabular}{|c|c|c|c|c|c|c|}
\hline \multirow{2}{*}{ Factor } & \multicolumn{6}{|c|}{ Particle Size Range $[\mu \mathrm{m}]$} \\
\hline & $0.3-0.5$ & $0.5-1.0$ & $1.0-2.5$ & $2.5-5.0$ & $5.0-10.0$ & $>10.0$ \\
\hline Wind speed & $-0.33^{* *}$ & $-0.36^{* *}$ & $0.26^{* *}$ & $0.34 * *$ & $0.28 * *$ & $0.19^{* *}$ \\
\hline Temperature & $0.34^{* *}$ & 0.09 & $-0.27 * *$ & $-0.19 * *$ & $-0.11 *$ & -0.04 \\
\hline $\mathrm{RH}$ & $-0.40^{* *}$ & $-0.31^{* *}$ & $0.32 * *$ & $0.47^{* *}$ & $0.40 * *$ & $0.29^{* *}$ \\
\hline
\end{tabular}

\subsection{Relationships between Noise Indicators and Particle Number Concentration}

Correlation analyses between the noise parameters and PNCs was carried out and the results are listed in Table 11. It was found that the correlation tendencies between the noise parameters and PNC differed according to the particle size implying that appropriate noise parameters to represent the PNC may differ depending on the particle size. 
Table 11. Correlation coefficients between the noise levels and particle number concentration.

\begin{tabular}{|c|c|c|c|c|c|c|c|}
\hline Particle Size Range & $L_{\mathrm{eq}}$ & $L_{90}$ & $L_{50}$ & $L_{10}$ & $L_{\mathrm{OLF}}$ & $L_{\mathrm{HLF}}$ & $L_{\mathrm{HF}-\mathrm{LF}}$ \\
\hline $0.3-0.5 \mu \mathrm{m}$ & $0.61^{* *}$ & $0.57^{* *}$ & $0.58^{* *}$ & $0.61^{* *}$ & $0.36^{* *}$ & $-0.62 * *$ & $-0.47^{* *}$ \\
\hline $0.5-1.0 \mu \mathrm{m}$ & $0.56^{* *}$ & $0.50 * *$ & $0.52 * *$ & $0.57^{* *}$ & $0.43^{* *}$ & $-0.59 * *$ & $-0.51^{* *}$ \\
\hline $1.0-2.5 \mu \mathrm{m}$ & -0.07 & -0.10 & -0.10 & -0.08 & $-0.30^{* *}$ & 0.04 & $0.27^{* *}$ \\
\hline $2.5-5.0 \mu \mathrm{m}$ & $-0.53^{* *}$ & $-0.55^{* *}$ & $-0.53^{* *}$ & $-0.52 * *$ & $-0.62 * *$ & $0.35 * *$ & $0.63^{* *}$ \\
\hline $5.0-10.0 \mu \mathrm{m}$ & $-0.54^{* *}$ & $-0.56^{* *}$ & $-0.53^{* *}$ & $-0.53 * *$ & $-0.60 * *$ & $0.36^{* *}$ & $0.61^{* *}$ \\
\hline$>10.0 \mu \mathrm{m}$ & $-0.49^{* *}$ & $-0.51^{* *}$ & $-0.48^{* *}$ & $-0.48^{* *}$ & $-0.51^{* *}$ & $0.33^{* *}$ & $0.52 * *$ \\
\hline
\end{tabular}

The PNCs for particle sizes of 0.3-1.0 $\mu \mathrm{m}$ showed statistically positive relationships with $L_{\mathrm{eq}}$ and the percentile noise levels, whereas negative correlations were observed for particles larger than $2.5 \mu \mathrm{m}$. Significant correlations were not observed between $L_{\mathrm{eq}}$ and particle sizes of 1.0-2.5 $\mu \mathrm{m}$. Similarly, $L_{\mathrm{OLF}}$ had positive and negative correlations with particle sizes in the range of 0.3-2.5 $\mu \mathrm{m}$ and larger than $2.5 \mu \mathrm{m}$, respectively. These results can be explained by the correlations between traffic parameters, noise indicators, and particle sizes of the PNCs in this study, as illustrated in Figure 8. The PNCs of larger particle sizes $(>2.5 \mu \mathrm{m})$ showed positive correlations with traffic speed, as shown in Table 5 . The noise indicators $L_{\mathrm{eq}}$ and $L_{\mathrm{OLF}}$ had strong negative correlations with traffic speed and larger particles $(>2.5 \mu \mathrm{m})$, as shown in Table 3. Based on these relationships, one can see that the $L_{\mathrm{eq}}$ and $L_{\mathrm{OLF}}$ could be utilized as noise indicators to predict the PNCs of larger particles $(>2.5 \mu \mathrm{m})$.

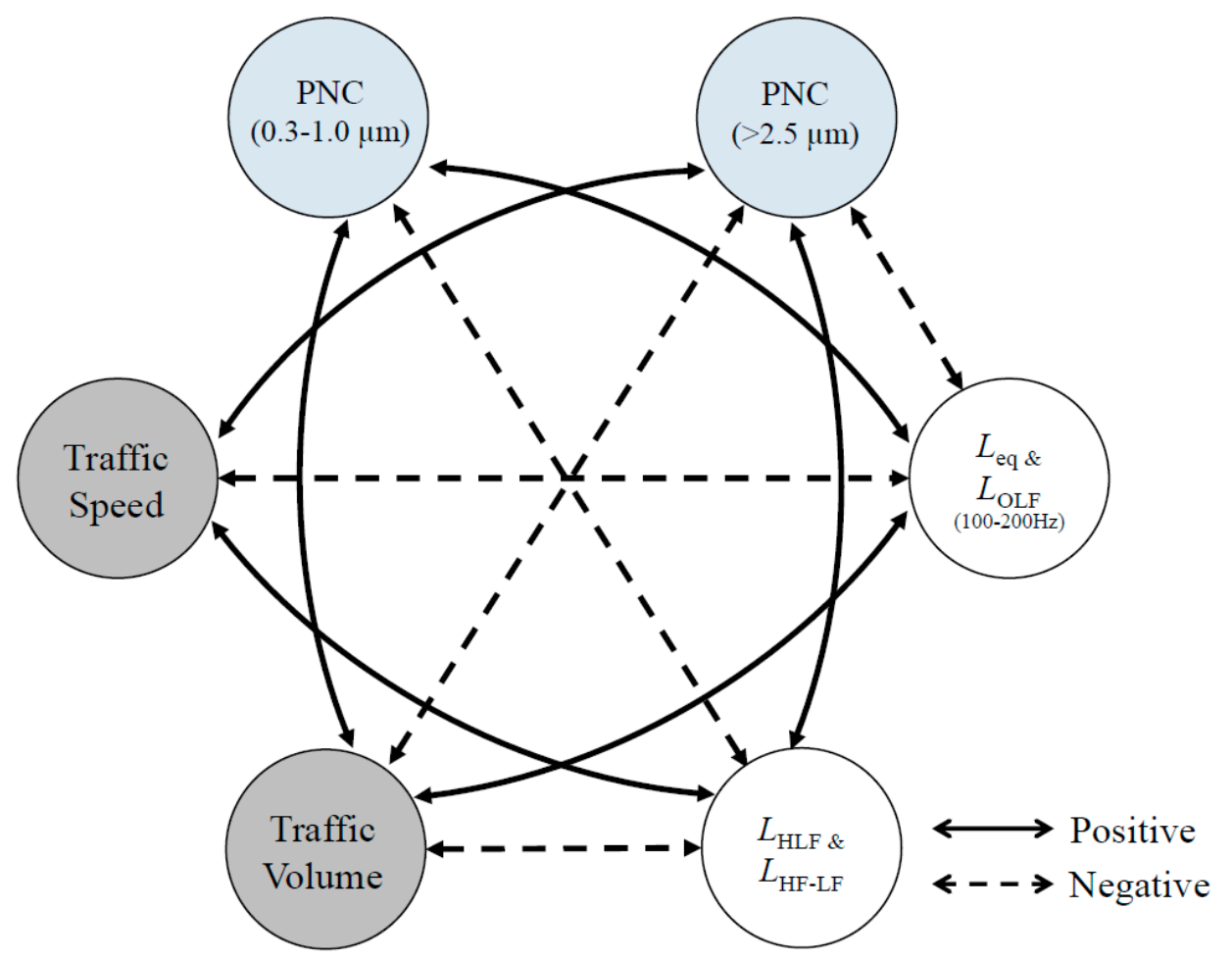

Figure 8. Summary of relationships between traffic parameters, noise indicators, and PNCs based on our measurements.

In contrast to $L_{\mathrm{OLF}}$ and $L_{\mathrm{eq}}$, the high-frequency noise indicators $L_{\mathrm{HLF}}$ and $L_{\mathrm{HF}-\mathrm{LF}}$ showed negative correlations with submicron particles $(0.3-1.0 \mu \mathrm{m})$, but positive correlations with particles larger than $2.5 \mu \mathrm{m}$. As illustrated in Figure 8, the traffic volume on closer road sections showed positive correlation with the PNCs of submicron particles $(0.3-1.0 \mu \mathrm{m})$. Additionally, it was found that high-frequency noise indicators were negatively associated with traffic volume. These findings indicate that $L_{\mathrm{HLF}}$ and $L_{\mathrm{HF}-\mathrm{LF}}$ can be utilized to predict the PNCs of submicron particles $(0.3-1.0 \mu \mathrm{m})$. 


\section{Discussion}

Based on in-situ measurements carried for $24 \mathrm{~h}$, it was revealed that there are significant correlations among the noise levels, PNC, and traffic parameters. Overall, traffic closer to the measurement position, as is the case with $\mathrm{T} 1$ and $\mathrm{T} 2$, had more of an influence on the noise parameters and PNC than the distant expressway, T3. Even though the traffic parameter at T3 is much greater than the other roads, the traffic on T3 mainly contributes to stationary background noise levels and the PNC for the measurement site. This indicates that local variations of the noise levels and particle distributions may be influenced by not only the traffic volume but also the distance from the roads.

It was observed that the temporal patterns of noise, traffic, and PNC varied depending on the time of day or night. This finding was in good agreement with the results of previous studies in which there are significant differences of noise and air pollutants between day and night [40,42]. Interestingly, the relationship between the noise parameters and PNC also differed according to the particle size. To evaluate the extent of the correlations among the noise and PNC according to the day and night time periods, the correlation coefficients were calculated, as presented in Table 12. According to EEA, daytime is defined as the hours from 07:00 until 22:00 and nighttime is the period from 22:00-07:00. The particle numbers were aggregated in terms of particle sizes in the ranges of $0.3-1.0 \mu \mathrm{m}$ and $>2.5 \mu \mathrm{m}$.

Table 12. Correlation coefficients between the noise parameters and PNC for the daytime (07:00-22:00) and nighttime (23:00-06:00).

\begin{tabular}{|c|c|c|c|c|c|}
\hline PNC & Period & $L_{\mathrm{eq}}$ & $L_{\mathrm{OLF}}$ & $L_{\mathrm{HLF}}$ & $L_{\text {HF-LF }}$ \\
\hline \multirow{2}{*}{$0.3-1.0 \mu \mathrm{m}$} & Day & $0.54^{* *}$ & $0.16^{*}$ & $-0.43^{* *}$ & $-0.27^{* *}$ \\
\hline & Night & -0.02 & -0.14 & $-0.70^{* *}$ & -0.03 \\
\hline \multirow{2}{*}{$>2.5 \mu \mathrm{m}$} & Day & $-0.19 * *$ & $-0.34^{* *}$ & 0.05 & $0.30 * *$ \\
\hline & Night & $-0.32^{* *}$ & $-0.29^{* *}$ & 0.20 & $0.34^{* *}$ \\
\hline
\end{tabular}

With regards to noise parameters, the overall noise level $\left(L_{\mathrm{eq}}\right)$ and low frequency noise level ( $L_{\mathrm{OLF}}$ ) showed positive correlations with the PNC at 0.3-1.0 $\mu \mathrm{m}$ during the daytime, while significant correlations were not found between the noise parameters and submicron particles during the nighttime. These findings demonstrate that the submicron particles are strongly related to traffic volumes at daytime. Only the high frequency noise level $\left(L_{\mathrm{HLF}}\right)$ exhibited strong and negative correlations with the number of submicron particles $(r=-0.70, p<0.01)$. This may be because of the noise emissions spectra of vehicles with high traffic speeds and less confounding by other ambient noise sources in nighttime periods [42].

The PNC with particles larger than $2.5 \mu \mathrm{m}$ was strongly correlated with the low and high frequency characteristics of the noises and the correlations during the day and night. The correlation strengths during the day and night were not significantly different. This implies that the relationship between the PNC at $>2.5 \mu \mathrm{m}$ and noise parameters were consistent over the whole measurement period.

Stepwise multiple regression analyses were conducted using a linear combination of noise and meteorological parameters to obtain optimal models to estimate the PNC depending on the particle size. Equations (1) and (2) show the prediction models of PNC for 0.3-1.0 $\mu \mathrm{m}$ and $>2.5 \mu \mathrm{m}$ particles with standardized regression coefficients, respectively. As shown in Equation (1), three variables, $L_{\mathrm{HLF}}$, $L_{\text {eq, }}$ and $\mathrm{RH}$, were selected to estimate the PNC for submicron particles. The regression model could explain approximately $54 \%$ of the variance in the PNC for particle sizes in the range of $0.3-1.0 \mu \mathrm{m}$. The standardized partial regression coefficients for $L_{\mathrm{HLF}}, L_{\mathrm{eq}}$, and $\mathrm{RH}$ were $-0.54,0.55$, and 0.33 , respectively. This indicates that the contributions of $L_{\mathrm{HLF}}$ and $L_{\mathrm{eq}}$ to the PNC $(0.3-1.0 \mu \mathrm{m})$ are similar, while the influence of the RH is relatively small. As shown in Equation (2), the stepwise regression model for larger particles showed that $L_{\mathrm{OLF}}$ and $L_{\mathrm{eq}}$ are significant predictors for the PNC of particles $>2.5 \mu \mathrm{m}\left(R^{2}=0.40\right)$. Particularly, the contribution of $L_{\mathrm{OLF}}$ in the estimation of the PNC $(>2.5 \mu \mathrm{m})$ is twice as large as that of $L_{\mathrm{eq}}$. These findings indicate that the noise parameters representing the overall 
levels and frequency characteristics of noise may be used to explain the relationship between noise and air pollution in urban areas.

$$
\begin{gathered}
P N C_{0.3-1.0 \mu \mathrm{m}} \approx-0.54 L_{H L F}+0.55 L_{e q}+0.33 R H\left(R^{2}=0.54, p<0.001\right) \\
P N C_{>2.5 \mu \mathrm{m}} \approx-0.46 L_{O L F}-0.23 L_{e q}\left(R^{2}=0.40, p<0.001\right)
\end{gathered}
$$

\section{Conclusions}

Based on field measurements obtained over $24 \mathrm{~h}$ in an urban area, strong correlations between noise, traffic, and PNC were revealed. Traffic parameters, including volume and speed, affected both the noise and PNC, confirming that they are common sources of noise and air pollution. In particular, the spectral characteristics of noise were closely associated with traffic volume and speed, which also showed significant correlations with PNC. The relationship between the noise and PNC differed depending on the particle size. Regarding noise indicators, PNC $(0.3-1.0 \mu \mathrm{m})$ showed stronger correlations with $L_{\mathrm{HLF}}$, whereas $L_{\mathrm{OLF}}$ had stronger correlations with larger particles $(>2.5 \mu \mathrm{m})$. The overall noise level $L_{\text {eq }}$ showed significant correlations with both smaller $(0.3-1.0 \mu \mathrm{m})$ and larger $(>2.5 \mu \mathrm{m})$ PNCs. PNC $(0.3-1.0 \mu \mathrm{m})$ showed a stronger correlation with noise during the daytime, but relatively consistent relationships were observed between the PNC $(>2.5 \mu \mathrm{m})$ and noise parameters for both day and night periods. These results support the idea that frequency-specific noise indicators and traffic data provide useful knowledge regarding the relationships between noise and air pollutants in urban environments. Furthermore, the findings of this study demonstrate the importance of monitoring temporally-resolved and spectral-specific air and noise pollutants to better understand community exposure and the health impacts of air and noise pollution.

Despite the significance of our findings, inherent limitations remain in our study. A measurement period of $24 \mathrm{~h}$ limits our ability to characterize the relationships between noise, traffic, and air pollution. Therefore, long-term studies across multiple seasons and spaces are required to validate these relationships. Additionally, some factors that might affect noise and air pollution were not considered in this present study. For example, although the distance to road sections could play a key role in noise and air pollution, the effects of the distances of sources were not explored in depth because our measurement location considered three road sections at different distances. Therefore, the relationship between the distance to a road section and PNCs should be investigated in the future. Furthermore, vehicle compositions (e.g., proportions of light and heavy vehicles on road sections) and the fuel types of vehicles (e.g., electric, diesel, or gasoline vehicles) could be critical factors in future studies because the emission rate of both the frequency content of noise and particulate matter varies according to the types of vehicles and fuel types. Finally, it should be noted that some results may be masked by other sources of air-noise pollution near the measurement location, which were not identified in this study.

Author Contributions: Conceptualization, J.Y.J., J.Y.H. and K.H.K.; Data curation, K.H.K.; Formal analysis, J.Y.H and S.M.K.; Methodology, J.Y.H.; Writing—original draft, J.Y.H; Writing—review \& editing, J.Y.H., S.M.K., and J.Y.J.

Funding: This work was supported by a grant the Global Frontier R\&D Program on "Human-centered Interaction for Coexistence," from the National Research Foundation of Korea which was funded by the Korean government (MSIP) (2013M3A6A3079356).

Conflicts of Interest: The authors declare no conflict of interest.

\section{References}

1. Pedersen, E. City dweller responses to multiple stressors intruding into their homes: Noise, light, odour, and vibration. Int. J. Environ. Res. Public Health 2015, 12, 3246-3263. [CrossRef] [PubMed] 
2. WHO Regional Office for Europe. Environmental Noise Guidelines for the European Region; World Health Organization: Geneva, Switzerland, 2018; ( http:/ /www.euro.who.int/en/publications/abstracts / environmental-noise-guidelines-for-the-european-region-201).

3. Fritschi, L.; Brown, A.L.; Kim, R.; Schwela, D.; Kephalopoulos, S. Burden of Disease from Environmental Noise: Quantification of Healthy Life Years Lost in Europe; World Health Organization: Geneva, Switzerland, 2011. (https://www.who.int/quantifying_ehimpacts/publications/e94888/en/).

4. Kim, K.; Kabir, E.; Kabir, S. A review on the human health impact of airborne particulate matter. Environ. Int. 2015, 74, 136-143. [CrossRef] [PubMed]

5. Kim, K.H.; Jahan, S.A.; Kabir, E. A review on human health perspective of air pollution with respect to allergies and asthma. Environ. Int. 2013, 59, 41-52. [CrossRef] [PubMed]

6. Allen, R.W.; Adar, S.D. Are both air pollution and noise driving adverse cardiovascular health effects from motor vehicles? Environ. Res. 2011, 111, 184-185. [CrossRef] [PubMed]

7. Kampa, M.; Castanas, E. Human health effects of air pollution. Environ. Pollut. 2008, 151, 362-367. [CrossRef] [PubMed]

8. Seaton, A.; MacNee, W.; Donaldson, K.; Godden, D. Particulate air pollution and acute health effects. Lancet 1995, 345, 176-178. [CrossRef]

9. Harrison, R.M.; Yin, J. Particulate matter in the atmosphere: Which particle properties are important for its effects on health? Sci. Total Environ. 2000, 249, 85-101. [CrossRef]

10. Kumar, P.; Morawska, L.; Birmili, W.; Paasonen, P.; Hu, M.; Kulmala, M.; Harrison, R.M.; Norford, L.; Britter, R. Ultrafine particles in cities. Environ. Int. 2014, 66, 1-10. [CrossRef] [PubMed]

11. Zhang, K.M.; Wexler, A.S. Evolution of particle number distribution near roadways-Part I: Analysis of aerosol dynamics and its implications for engine emission measurement. Atmos. Environ. 2004, 38, 6643-6653. [CrossRef]

12. Stölzel, M.; Breitner, S.; Cyrys, J.; Pitz, M.; Wölke, G.; Kreyling, W.; Heinrich, J.; Wichmann, H.-E.; Peters, A. Daily mortality and particulate matter in different size classes in Erfurt, Germany. J. Expo. Sci. Environ. Epidemiol. 2007, 17, 458-467. [CrossRef]

13. Dimitriou, K.; Paschalidou, A.K.; Kassomenos, P.A. Assessing air quality with regards to its effect on human health in the European Union through air quality indices. Ecol. Indic. 2013, 27, 108-115. [CrossRef]

14. Fujiwara, F.G.; Gómez, D.R.; Dawidowski, L.; Perelman, P.; Faggi, A. Metals associated with airborne particulate matter in road dust and tree bark collected in a megacity (Buenos Aires, Argentina). Ecol. Indic. 2011, 11, 240-247. [CrossRef]

15. Śliwińska-Kowalska, M.; Zaborowski, K. WHO environmental noise guidelines for the European Region: A systematic review on environmental noise and permanent hearing loss and tinnitus. Int. J. Environ. Res. Public Health 2017, 14, 1139. [CrossRef] [PubMed]

16. Berglund, B.; Lindvall, T.; Schwela, D.; Goh, K.T. Guidelines for Community Noise; World Health Organization: Geneva, Switzerland, 1999; ( http:/ / apps.who.int/iris/handle/10665/66217).

17. Stansfeld, S.A.; Matheson, M.P. Noise pollution: Non-auditory effects on health. Br. Med. Bull. 2003, 68, 243-257. [CrossRef] [PubMed]

18. Hanines, M.M.; Stansfeld, S.A.; Job, R.F.S.; Berglund, B.; Head, J. Chronic aircraft noise exposure, stress responses, mental health and cognitive performance in school children. Psychol. Med. 2001, 31, $265-277$.

19. Spreng, M. Central nervous system activation by noise. Noise Heal. 2000, 2, $49-57$.

20. Babisch, W.; Pershagen, G.; Selander, J.; Houthuijs, D.; Breugelmans, O.; Cadum, E.; Vigna-Taglianti, F.; Katsouyanni, K.; Haralabidis, A.S.; Dimakopoulou, K.; et al. Noise annoyance-A modifier of the association between noise level and cardiovascular health? Sci. Total Environ. 2013, 452-453, 50-57. [CrossRef] [PubMed]

21. Fyhri, A.; Aasvang, G.M. Noise, sleep and poor health: Modeling the relationship between road traffic noise and cardiovascular problems. Sci. Total Environ. 2010, 408, 4935-4942. [CrossRef]

22. Jarup, L.; Babisch, W.; Houthuijs, D.; Pershagen, G.; Katsouyanni, K.; Cadum, E.; Dudley, M.-L.; Savigny, P.; Seiffert, I.; Swart, W.; et al. Hypertension and Exposure to Noise Near Airports: The HYENA Study. Environ. Health Perspect. 2008, 116, 329-333. [CrossRef]

23. Davies, H.W.; Vlaanderen, J.J.; Henderson, S.B.; Brauer, M. Correlation between co-exposures to noise and air pollution from traffic sources. Occup. Environ. Med. 2009, 66, 347-350. [CrossRef] 
24. Stansfeld, S.A.; Berglund, B.; Clark, C.; Lopez-Barrio, I.; Fischer, P.; Öhrström, E.; Haines, M.M.; Head, J.; Hygge, S.; Van Kamp, I.; et al. Aircraft and road traffic noise and children's cognition and health: A cross-national study. Lancet 2005, 365, 1942-1949. [CrossRef]

25. Schultz, T.J. Synthesis of social surveys on noise annoyance. J. Acoust. Soc. Am. 1978, 64, 377-405. [CrossRef] [PubMed]

26. Hygge, S.; Evans, G.W.; Bullinger, M. A prospective study of some effects of aircraft noise on cognitive performance in schoolchildren. Psychol. Sci. 2002, 13, 469-474. [CrossRef] [PubMed]

27. Jeon, J.Y.; Hong, J.Y.; Jang, H.S.; Kim, J.H. Speech privacy and annoyance considerations in the acoustic environment of passenger cars of high-speed trains. J. Acoust. Soc. Am. 2015, 138, 3976-3984. [CrossRef] [PubMed]

28. HME, M. Relationship between exposure to multiple noise sources and noise annoyance. J. Acoust. Soc. Am. 2004, 116, 949-957.

29. Venetjoki, N.; Kaarlela-Tuomaala, A.; Keskinen, E.; Hongisto, V. The effect of speech and speech intelligibility on task performance. Ergonomics 2006, 49, 1068-1091. [CrossRef] [PubMed]

30. Aasvang, G.M.; Engdahl, B.; Rothschild, K. Annoyance and self-reported sleep disturbances due to structurally radiated noise from railway tunnels. Appl. Acoust. 2007, 68, 970-981. [CrossRef]

31. Janssen, S.A.; Centen, M.R.; Vos, H.; Van Kamp, I. The effect of the number of aircraft noise events on sleep quality. Appl. Acoust. 2014, 84, 9-16. [CrossRef]

32. Lercher, P.; van Kamp, I.; von Lindern, E.; Botteldooren, D. Perceived soundscapes and health-related quality of life, context, restoration, and personal characteristics. In Soundscape and the Built Environment; Kang, J., Schulte-Fortkamp, B., Eds.; CRC Press: London, UK, 2015.

33. Benson, P.E. A review of the development and application of the CALINE3 and 4 models. Atmos. Environ. Part B. Urban Atmos. 1992, 26, 379-390. [CrossRef]

34. Steele, C. A critical review of some traffic noise prediction models. Appl. Acoust. 2001, 62, 271-287. [CrossRef]

35. Peters, A.; von Klot, S.; Heier, M.; Trentinaglia, I.; Hormann, A.; Wichmann, H.E.; Lowel, H. Exposure to Traffic and the Onset of Myocardial Infarction. New Engl. J. 2008, 427-437. [CrossRef]

36. King, E.A.; Bourdeau, E.P.; Zheng, X.Y.K.; Pilla, F. A combined assessment of air and noise pollution on the High Line, New York City. Transp. Res. Part D Transp. Environ. 2016, 42, 91-103. [CrossRef]

37. Allen, R.W.; Davies, H.; Cohen, M.A.; Mallach, G.; Kaufman, J.D.; Adar, S.D. The spatial relationship between traffic-generated air pollution and noise in 2 US cities. Environ. Res. 2009, 109, 334-342. [CrossRef] [PubMed]

38. Kheirbek, I.; Ito, K.; Neitzel, R.; Kim, J.; Johnson, S.; Ross, Z.; Eisl, H.; Matte, T. Spatial variation in environmental noise and air pollution in New York City. J. Urban Heal. 2014, 91, 415-431. [CrossRef] [PubMed]

39. Tang, U.W.; Wang, Z.S. Influences of urban forms on traffic-induced noise and air pollution: Results from a modelling system. Environ. Model. Softw. 2007, 22, 1750-1764. [CrossRef]

40. Kim, K.H.; Ho, D.X.; Brown, R.J.C.; Oh, J.M.; Park, C.G.; Ryu, I.C. Some insights into the relationship between urban air pollution and noise levels. Sci. Total Environ. 2012, 424, 271-279. [CrossRef] [PubMed]

41. Fecht, D.; Hansell, A.L.; Morley, D.; Dajnak, D.; Vienneau, D.; Beevers, S.; Toledano, M.B.; Kelly, F.J.; Anderson, H.R.; Gulliver, J. Spatial and temporal associations of road traffic noise and air pollution in London: Implications for epidemiological studies. Environ. Int. 2016, 88, 235-242. [CrossRef] [PubMed]

42. Ross, Z.; Kheirbek, I.; Clougherty, J.E.; Ito, K.; Matte, T.; Markowitz, S.; Eisl, H. Noise, air pollutants and traffic: Continuous measurement and correlation at a high-traffic location in New York City. Environ. Res. 2011, 111, 1054-1063. [CrossRef]

43. Weber, S.; Litschke, T. Variation of particle concentrations and environmental noise on the urban neighbourhood scale. Atmos. Environ. 2008, 42, 7179-7183. [CrossRef]

44. Dekoninck, L.; Botteldooren, D.; Int Panis, L. An instantaneous spatiotemporal model to predict a bicyclist's Black Carbon exposure based on mobile noise measurements. Atmos. Environ. 2013, 79, 623-631. [CrossRef]

45. Dekoninck, L.; Botteldooren, D.; Int, L.; Hankey, S.; Jain, G.; Karthik, S.; Marshall, J. Applicability of a noise-based model to estimate in traffic exposure to black carbon and particle number concentrations in different cultures. Environ. Int. 2015, 74, 89-98. [CrossRef] [PubMed]

46. Borm, P.J.A.; Robbins, D.; Haubold, S.; Kuhlbusch, T.; Fissan, H.; Donaldson, K.; Schins, R.; Stone, V.; Kreyling, W.; Lademann, J.; et al. The potential risks of nanomaterials: A review carried out for ECETOC. Part. Fibre Toxicol. 2006, 3, 11. [CrossRef] [PubMed] 
47. Weber, S. Spatio-temporal covariation of urban particle number concentration and ambient noise. Atmos. Environ. 2009, 43, 5518-5525. [CrossRef]

48. Zhang, K.M.; Wexler, A.S.; Niemeier, D.A.; Yi, F.Z.; Hinds, W.C.; Sioutas, C. Evolution of particle number distribution near roadways. Part III: Traffic analysis and on-road size resolved particulate emission factors. Atmos. Environ. 2005, 39, 4155-4166. [CrossRef]

49. Boogaard, H.; Borgman, F.; Kamminga, J.; Hoek, G. Exposure to ultrafine and fine particles and noise during cycling and driving in 11 Dutch cities. Atmos. Environ. 2009, 43, 4234-4242. [CrossRef]

50. Yang, D.; Wang, Z.; Li, B.; Luo, Y.; Lian, X. Quantitative measurement of pass-by noise radiated by vehicles running at high speeds. J. Sound Vib. 2011, 330, 1352-1364. [CrossRef]

51. Cho, C. Traffic noise characteristic of urban major roads by the traffic flow conditions. J. Korean Soc. Living Environ. Syst. 2010, 10, 585-594.

52. ISO 1996-2. Acoustics—Description, Measurement and Assessment of Environmental Noise—Part 2: Determination of Sound Pressure Levels; International Organization for Standardization: Geneva, Switzerland, 2017.

53. Ning, Z.; Hudda, N.; Daher, N.; Kam, W.; Herner, J.; Kozawa, K.; Mara, S.; Sioutas, C. Impact of roadside noise barriers on particle size distributions and pollutants concentrations near freeways. Atmos. Environ. 2010, 44, 3118-3127. [CrossRef]

(C) 2018 by the authors. Licensee MDPI, Basel, Switzerland. This article is an open access article distributed under the terms and conditions of the Creative Commons Attribution (CC BY) license (http:/ / creativecommons.org/licenses/by/4.0/). 